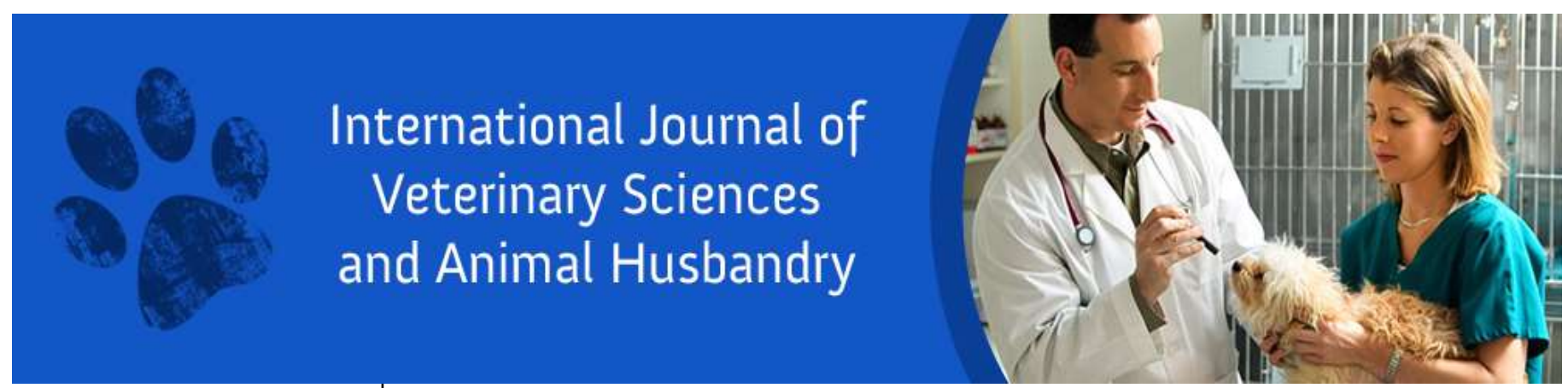

ISSN: $2456-2912$

VET 2021; 6(1): 11-14

(C) $2021 \mathrm{VET}$

www.veterinarypaper.com

Received: 26-07-2020

Accepted: 08-12-2020

\section{Deepa KP}

Department of Zoology, SNM College, Maliyankara, Kerala, India

\section{Sreeranjini AR}

Associate Professor, Department of Veterinary Anatomy and

Histology, College of Veterinary and Animal Sciences, Mannuthy,

Thrissur, Kerala, India

\section{Soumya CB}

Guest Lecturer, Department of Zoology, SNM College,

Maliyankara, Kerala, India

Maya S

Professor and Head, Department of Veterinary Anatomy and Histology, College of Veterinary and Animal Sciences, Mannuthy, Thrissur, Kerala, India

\section{Sunil Kumar NS}

Assistant Professors,

Department of Veterinary

Anatomy and Histology, College of Veterinary and Animal

Sciences, Mannuthy, Thrissur,

Kerala, India

\section{Sumena KB}

Assistant Professors,

Department of Veterinary Anatomy and Histology, College of Veterinary and Animal Sciences, Mannuthy, Thrissur, Kerala, India

\section{Comparative histological studies on the renal medulla in broiler chicken and broiler duck}

\author{
Deepa KP, Sreeranjini AR, Soumya CB, Maya S, Sunil Kumar NS and \\ Sumena KB
}

DOI: https://doi.org/10.22271/veterinary.2021.v6.i1a.316

\begin{abstract}
Kidneys of six each of adult broiler chicken and broiler ducks were used in the present study. In the histological studies, the kidneys of all studied birds showed two zones, the cortex and medulla. The medulla occupied only a small portion of the kidney. In chicken a greater number of distinct cone-shaped medullary lobules were seen among cortical lobules while in duck they were lesser in number, more rounded in outline and were not cone shaped as in chicken. In the case of chicken more than one cortical lobule drained into a medullary lobule. Mammalian type of nephrons that occupied the juxta medullary region presented loop of Henle that was located within the medullary cone. Collecting ducts from different medullary lobules united together to form several large collecting ducts within the medulla which in turn united to form ureteral branches.
\end{abstract}

Keywords: Broiler chicken, broiler duck, renal medulla, loop of henle, collecting ducts, histology

\section{Introduction}

Kidneys in birds are very important organs that help in water and electrolyte balance and consist of two zones in the histological studies; cortex and medulla. Nephrons are regarded as the structural and functional units of the kidneys. It helps to eliminate waste products and at the same time conserve materials like glucose and water. Broiler chicken and broiler duck inhabit a broad range of environments and ecological habitats. Hence their kidneys do not follow a similar pattern. Therefore, the present study was undertaken to investigate the comparative histology of the renal medulla in broiler chicken and broiler duck.

\section{Materials and Methods}

Kidneys of six each of adult broiler chicken and broiler ducks, slaughtered at the Meat Technology Unit, Mannuthy of Kerala Veterinary and Animal Sciences University were used to conduct the present study.

Kidneys of broiler chicken and broiler duck were carefully dissected out of the renal fossa and tissue samples were fixed at $10 \%$ neutral buffered formalin. Later they were processed for paraffin embedding and sectioned using rotary microtome. $5 \mu \mathrm{m}$ thick sections were stained with haematoxylin and eosin $(\mathrm{H} \& \mathrm{E})$. The histological features of kidney in broiler chicken and broiler duck were studied in detail and were recorded. Digital images were stored in Leica DM 2000 LED microscope.

\section{Results and discussion}

In the present study, kidneys of all birds comprised two zones viz. the cortex and medulla. The medulla occupied only a small portion of the kidney. Similarly, Michalek et al. (2016) ${ }^{[8]}$ noticed that the cortex constituted the majority, while the medulla formed only a small portion in the kidneys of emu (Dromaius novaehollandiae)
Corresponding Author: Deepa KP

Department of Zoology, SNM College, Maliyankara, Kerala, India 


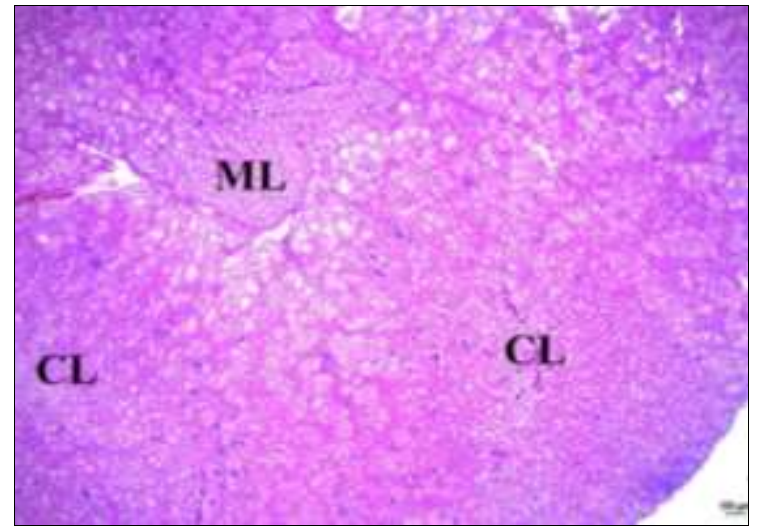

Fig 1: Section of kidney, Chicken. ML- Medullary lobule, CLCortical lobule. H\&E. x 40

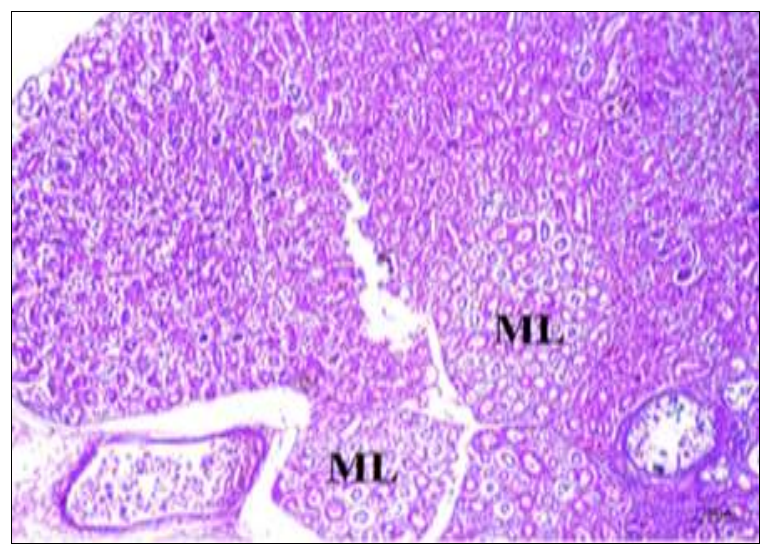

Fig 2: Section of kidney, Duck. ML- Medullary lobule. H\&E. x 100

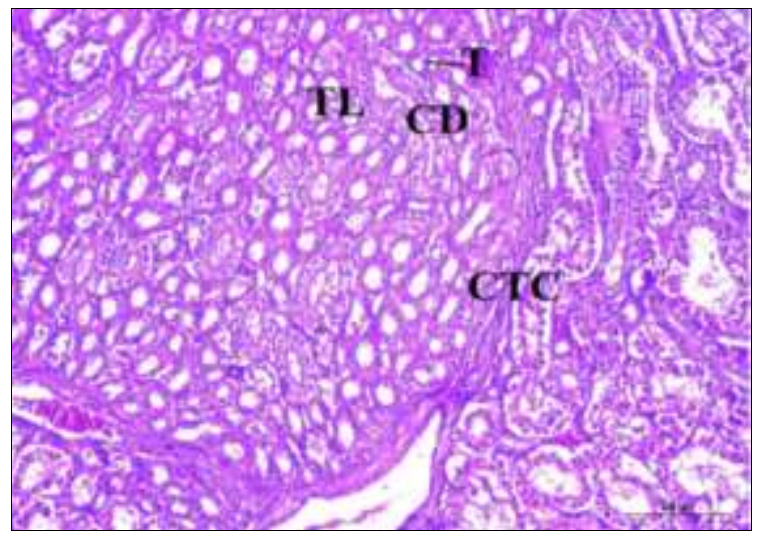

Fig 3: Section of kidney, Chicken. T- Thin limb, TL- Thick limb, CD- Collecting duct, CTC- Connective tissue covering of medullary lobule. H\&E. x 200

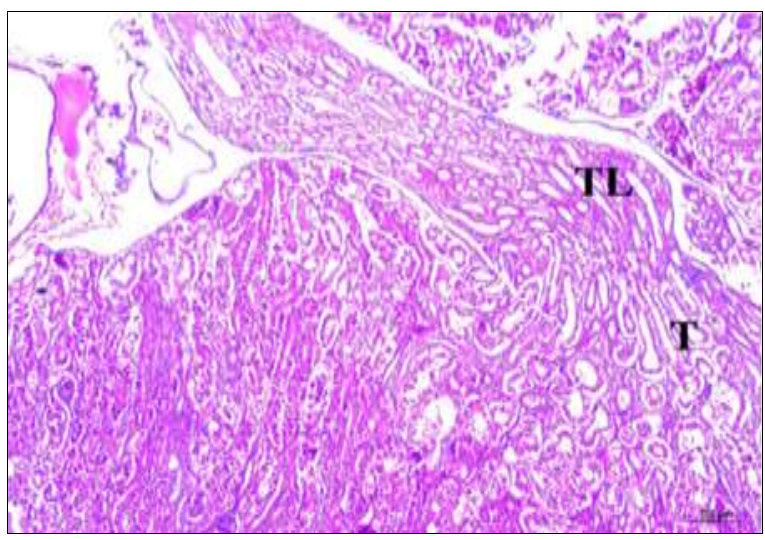

Fig 4: Section of kidney, Chicken. T- Thin limb, TL- Thick limb. H\&E. x 100

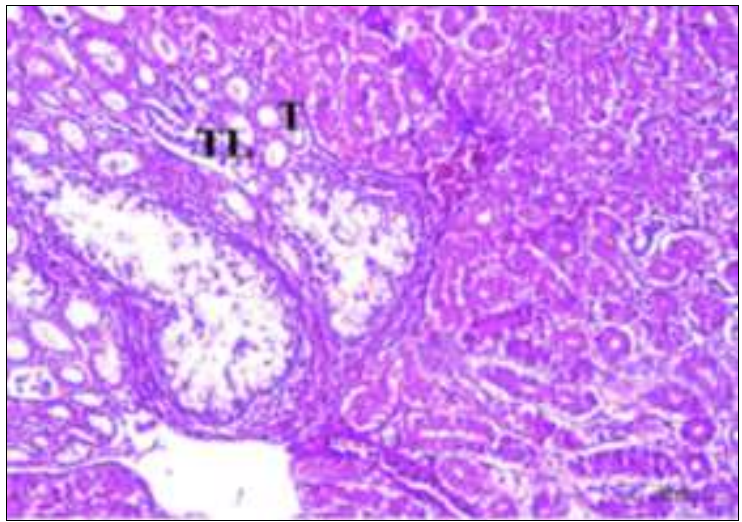

Fig 5: Section of kidney, Duck. T- Thin limb, TL- Thick limb. H\&E. x 200

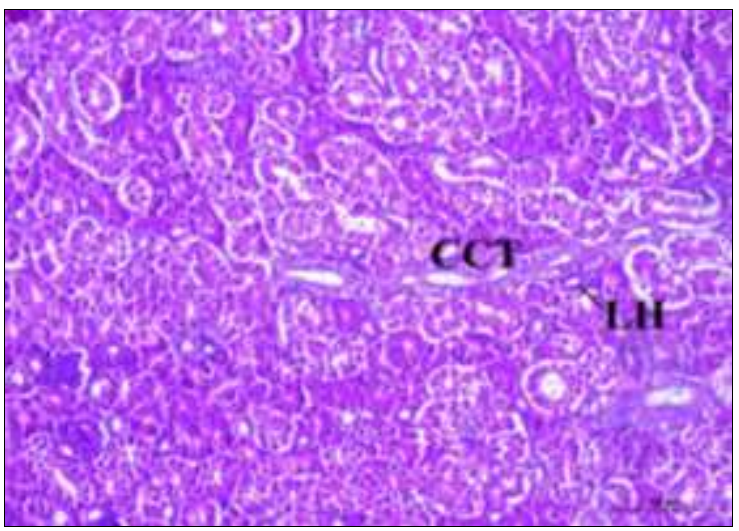

Fig 6: Section of kidney, Chicken. LH- Loop of Henle, CCTCortical collecting duct. H\&E. x 200

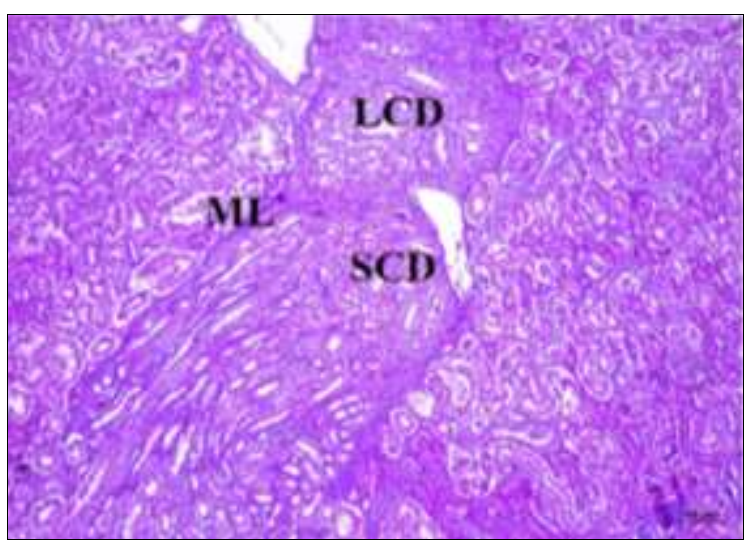

Fig 7: Section of kidney, Chicken. ML- Medullary lobule, SCDSmall collecting duct, LCD- Large collecting duct. H\&E. x 100

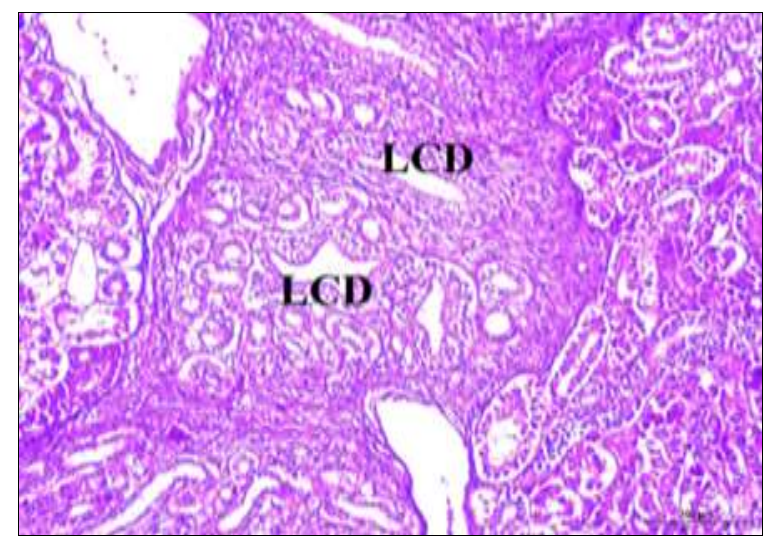

Fig 8: Section of kidney, Chicken. LCD- Large collecting duct. H\&E. x 200 


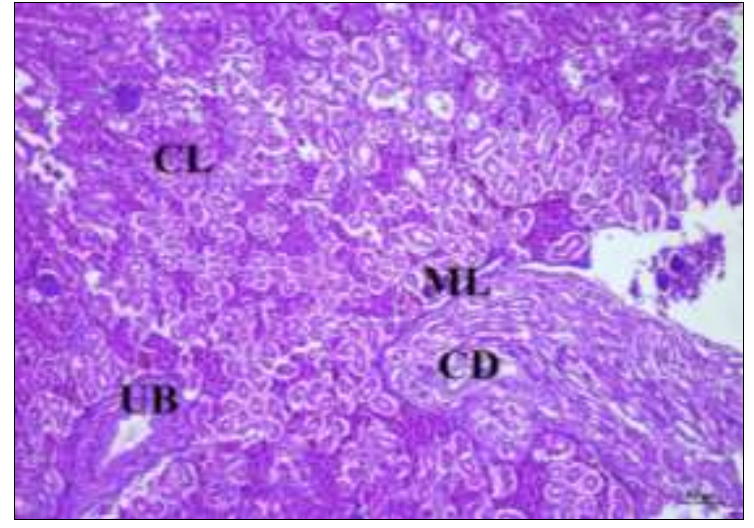

Fig 9: Section of kidney, Chicken. CL- Cortical lobule, MLMedullary lobule, CD- Collecting duct, UB- Ureteric branch H\&E. x 100

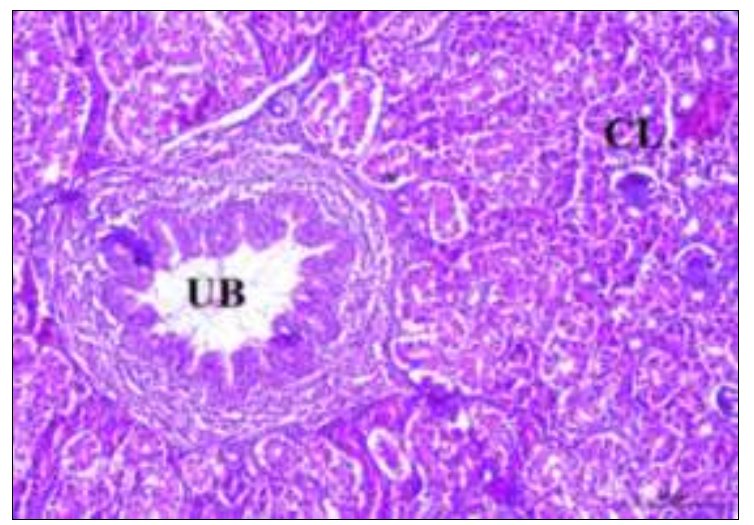

Fig 10: Section of kidney, Chicken. UB- Ureteric branch, CLCortical lobule. H\&E. x 200

\subsection{Medulla}

In broiler chicken a greater number of distinct cone-shaped medullary lobules were seen among cortical lobules and more than one cortical lobule drained into single medullary lobule (Fig. 1). Similar observations were made by Sreeranjini (2000) ${ }^{[9]}$ in the kidney of Japanese quail. In duck medullary lobules were lesser in number (Fig. 2), more rounded in outline and were not cone shaped as in chicken. Casotti et al. (2000) who reported that the avian medullary cones were structurally similar to the outer medulla of the mammalian kidney.

In the present study medullary lobules showed a distinct connective tissue covering and contained loops of Henle of juxtamedullary nephrons, vasa recta and collecting ducts of varying size (Fig. 3) identical to the findings of Sreeranjini et al. (2010) ${ }^{[10]}$ who found that the renal medulla in Japanese quail was in the form of cone-shaped medullary lobules with the loop of Henle of juxtamedullary nephrons, collecting ducts and vasa recta.

\subsection{Loop of Henle}

Reptilian type of small nephrons in the cortical region was lacking in the loop of Henle while the mammalian type of nephrons that occupied the juxtamedullary region presented loop of Henle that was located within the medulla. Abood et al. (2014) [1] reported that, in mallard duck there were numerous both mammalian and reptilian types of nephrons.

Thick limb of loop of Henle was lined by cuboidal cells with spherical nucleus and distinct nucleolus but in thin limb, the epithelium was lined by flattened cells with elliptical nucleus (Fig. $3 \& 4$ ) which was similar to the findings of Batah (2012) ${ }^{[3]}$ who noted that thick and thin segments of the loop of Henle in the kidney of coot birds were lined by simple cuboidal epithelium. In duck, both thick and thin limbs of the loop of Henle were lined by simple cuboidal cells (Fig. 5).

\subsection{Collecting tubules}

In the present study the cortical collecting tubules that were mostly seen in the periphery of cortical lobules were lined by simple columnar epithelial cells (Fig. 6). Hodges (1974) ${ }^{[5]}$ found that in the kidney of fowl, collecting tubules were lined by cuboidal or low columnar epithelium with large, round, vesicular, basal nuclei that contained one or two nucleoli.

Within medulla also the collecting ducts were lined by simple columnar epithelial cells (Fig. 3). They contained basal, spherical nuclei with distinct nucleolus and clear cytoplasm. Smaller collecting ducts united within the medullary cone to form larger collecting ducts (Figs. 7 and 8). Similar findings were made by Kurihara and Yasuda (1978) ${ }^{[6]}$ in the kidney of fowl. They reported that cross section of medullary lobules showed clump or rosette like arrangement of medullary collecting ducts that was formed by the union of several perilobular or cortical collecting ducts. Several large collecting ducts within the medulla united together to form ureteral branches (Fig. 9). They were seen in cortical region also (Fig.10) which in turn joined and formed the ureter. Similarly, Akester (1983) ${ }^{[2]}$ stated that in avian kidney cortical collecting ducts drained into peripheral collecting ducts which entered into the medulla and united to form a single large duct, the tertiary branch of the ureter.

\section{Conclusion}

In the present study, histological studies revealed that the renal medulla in both broiler chicken and duck occupied only a small portion. In chicken a greater number of distinct cones shaped medullary lobules were seen among cortical lobules while in the duck medullary lobules were lesser in number and more rounded in outline. The presence of a smaller number of mammalian type nephrons and medullary lobules in the kidney of broiler duck could be due to the aquatic habitat and feeding habit of the bird which enables it to consume more water through food. Due to higher access to water, these birds do not need to concentrate the urine as in the case of broiler chicken which are terrestrial birds. So, it was concluded that the renal medulla in broiler chicken and broiler duck showed differences in the pattern of arrangement of the various components.

\section{References}

1. Abood DA, Reshag AF, Azhar SK, Ahmed MA. Comparative anatomical and histological features of the kidney in Harrier (Circus aueroginosus), Chicken (Gallus domesticus) and Mallard duck (Anas platyrhynchos). Iraqi Journal of Veterinary Medicine 2014;38:107-113.

2. Akester AR. Anatomy of the avian kidney. In: Hall, L.W. (ed.). Veterinary Nephrology. William Heinemann Medical Books Ltd., London 1983, 26-56.

3. Batah AL. Morphological and histological study for the kidneys of coot bird (Fulica atra). Basrah Journal of Veterinary Research 2012;11:128-136.

4. Casotti G, Lindbery KK, Braun EJ. Functional morphology of the avian medullary cone. The American Journal of Physiology-Regulatory, Integrative and Comparative Physiology 2000;279:R1722-1730.

5. Hodges RD. The Urinary System. In: The Histology of the Fowl. Academic Press, London, New york, San Francisco 1974, 489-524. 
6. Kurihara S, Yasuda M. Morphological study on nephronium and ureteral system in the fowl. Japanese journal of veterinary research 1978;40:185-200.

7. Luna LG. Manual of histological staining methods of armed force Institute of pathology. $3^{\text {rd }}$ edition. New York USA 1968, 39-110.

8. Michalek K, Szczerbińska D, Grabowska M, Majewska D, Laszczyńska M. Anatomical and morphological study of the kidneys of the breeding Emu (Dromaius novaehollandiae). Turkish Journal of Zoology 2016;40(1):314-319.

9. Sreeranjini AR, Iyyangar MP, Gopinath S. Histological and histochemical studies in kidney of Japanese quail (Coturnix coturnix japonica). Indian journal of veterinary anatomy 2000;12:169-173.

10. Sreeranjini AR, Iyyangar MP, Pramodkumar D. Histological study of the renal medulla in Japanese quail. Indian journal of animal sciences 2010;80:539-540. 